\title{
EU legislation advancing ICT to green?
}

\author{
A. Hoelt ${ }^{1}$, R. Brandtweiner ${ }^{2}$ \& B. Fuhrmann ${ }^{3}$ \\ ${ }^{1}$ Department for Management and Economics, \\ Danube University Krems, Austria \\ ${ }^{2}$ Institute for Information Management \& Control, \\ Vienna University of Economics and Business, Austria \\ ${ }^{3}$ Institute for Business Education \\ Vienna University of Economics and Business, Austria
}

\begin{abstract}
The importance of information and communication technologies (ICTs) for society and economy has sharply increased during the last few decades. As a consequence, this sector's energy consumption and emissions have risen, too. However, ICT-enabled energy efficiency measures are expected to contribute to a reduction of carbon dioxide emissions by an astonishing 15 per cent. So Green IT is an essential precondition for the implementation of sustainable climate and energy policy targets. On the European Union level a set of Directives, Regulations and Communications affects the impact of ICTs on sustainability. This paper investigates the potentials and the effectivity of the present European Union legislation in this respect.

Keywords: ecodesign, energy efficiency, European legislation, Green IT, ICT, low carbon, renewable resources, RoHS, society, sustainabiltity, WEEE.
\end{abstract}

\section{Introduction}

Information and Communication Technologies (ICTs) have a crucial role towards achieving a sustainable and low carbon economy and society. ICTs have transformed our lifestyle and working environment significantly. Fig. 1 shows as an example the development of mobile-cellular subscriptions per 100 inhabitants worldwide, for developed and developing countries. Worldwide the number has nearly tripled from 34 mobile phones per 100 inhabitants in 2005 to 96 in 2013. The trend is the same for developing as well as for developed countries, though for the latter on a higher level. 


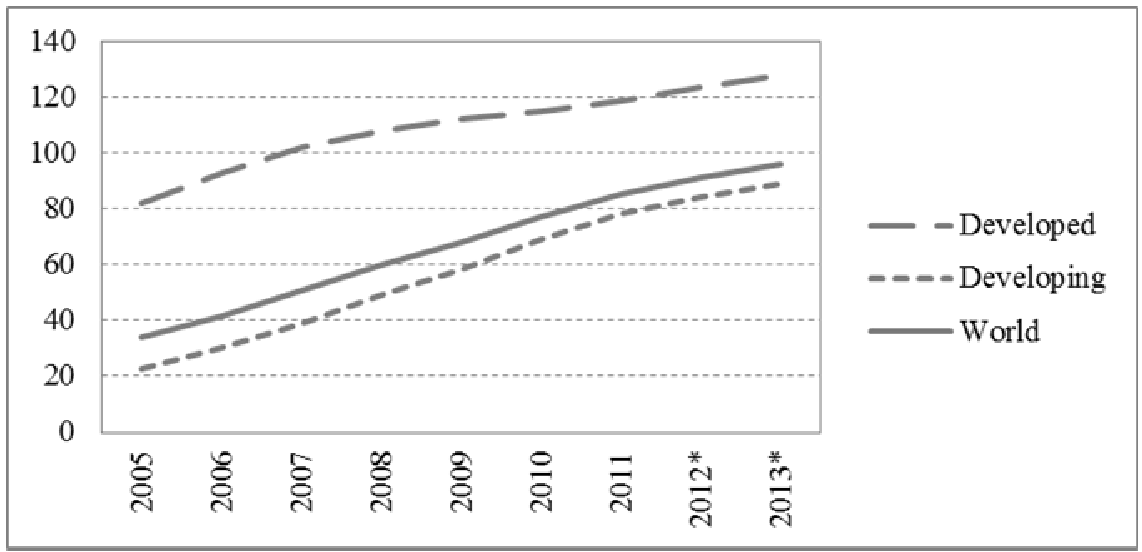

*Estimate.

Figure 1: Mobile-cellular subscriptions per 100 inhabitants, developed countries, developing countries and worldwide, 2005-2013 [1].

According to the SMART 2020 report of the Global e-Sustainability Initiative [2], in a business as usual scenario the carbon dioxide emissions of ICTs will increase from currently 0.9 gigaton $(\mathrm{Gt})$ to $1.43 \mathrm{Gt}$. ICTs are currently responsible for the same volume of carbon emissions as aviation. However, ICTenabled energy efficiency measures are expected to contribute to a reduction of the carbon dioxide emissions by an astonishing 15 per cent. Hence ICTs are a crucial tool for the implementation of the European Union's climate and energy policy towards achieving a low carbon society. Consequently ICTs have to be designed in a manner which promotes on the one hand a minimisation of energy consumption of the applied technology and on the other hand the extent of the contribution of ICTs to energy efficiency in many other sectors.

At the European Union level a set of Regulations and Directives is in force affecting the influence of ICTs on sustainability, for example the Directive $2006 / 32 / E C$ on energy end-use efficiency and energy services, the Directive 2002/96/EC on waste electrical and electronic equipment (WEEE), the Directive 2009/125/EC establishing a framework for the setting of ecodesign requirements for energy-related products or the Commission Regulation (EU) No $801 / 2013$ on ecodesign requirements. The possibility and requirement of the EU legislation regarding its effect on the impact of ICTs on environment and society are analysed in this paper.

\section{The relevance of ICT for sustainable development}

An advantage which is imputed to ICTs is their contribution to productivity, energy efficiency and reduction of carbon emissions. For example the European Commission in its Recommendation of 9 October 2009 "on mobilising Information and Communication Technologies to facilitate the transition to an 
energy-efficient, low carbon economy" [3] refers to the energy saving potential across industry and broader civil society of ICTs, but also emphasizes the increasing energy use by ICT equipment and services.

A widespread optimism about a mainly positive impact of ICTs on economic, energy and environmental systems has to be reviewed critically in relation to the full impact of ICTs, in order to establish this positive or even negative impact.

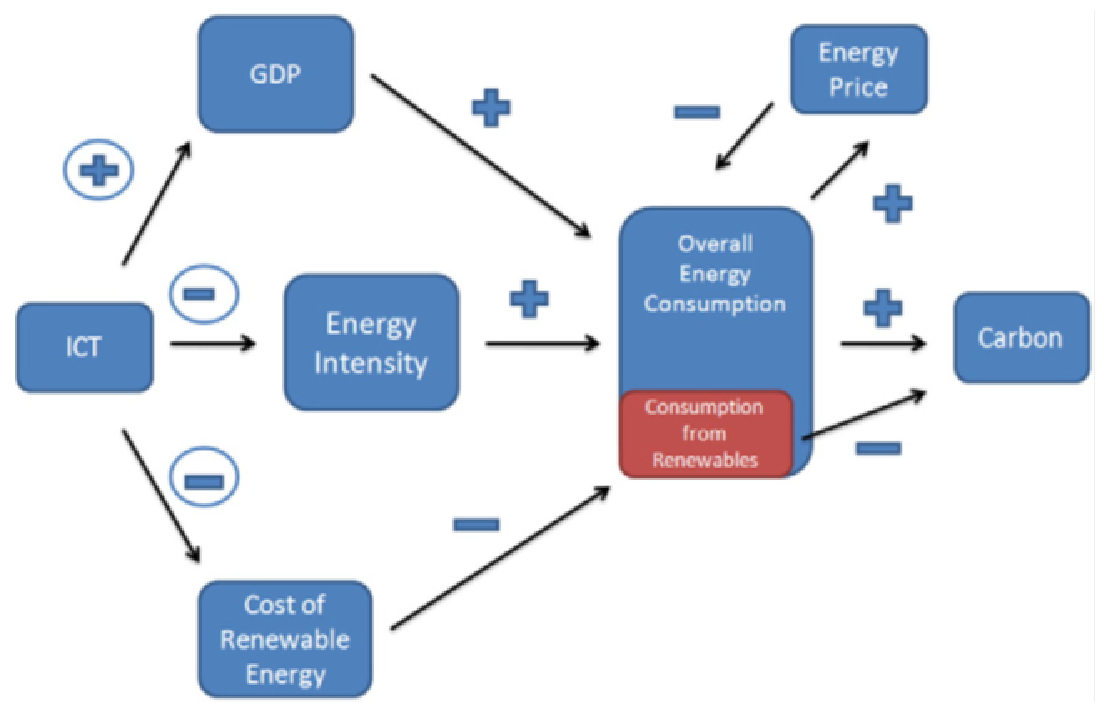

Figure 2: Conceptualising ICTs' impact on carbon emissions (Moyer and Hughes [4]).

Fig. 2 shows the impact of ICTs on GDP, on energy intensity and on the cost of renewable energy. For an estimation of an aggregate impact of ICTs on carbon emissions, these three categories as well as the development of energy prices and a feasible rebound effect [5] have to be considered. The analysis by Moyer and Hughes finds that ICTs actually have a positive impact on carbon dioxide reduction, although the positive net effect is not significant. The potential to reduce carbon emissions from both an increase of energy intensity and from the production of renewable energy is almost canceled out by the ICT's contribution to the GDP's increase. The main reason is the rebound effect of a decrease in energy prices caused by the two positive factors which leads to an increase of energy demand. Therefore Moyer and Hughes conclude that ICTs on their own cannot enable carbon emissions reduction effectively, but a combination with a regulation instrument like carbon pricing is needed.

\subsection{Energy consumption of ICT}

The business as usual (BAU) scenario of the SMART 2020 report estimates the global carbon emissions of the ICT sector with $1.43 \mathrm{GtCO}_{2} \mathrm{e}$ (gigaton carbon 
dioxide equivalent) for 2020. In 2002 the emissions were $0.53 \mathrm{GtCO}_{2} \mathrm{e}$, currently there are around $0.9 \mathrm{GtCO}_{2} \mathrm{e}$. Another estimation concerning the ICT sector's responsibility for global carbon emissions in the extent of $2 \%$ was available in 2007 [6]. This share will increase up to 6\% until 2020.

According to several estimates ICTs are responsible for $8 \%$ to $10 \%$ of the EU's electrical power consumption and for $2.5 \%$ to $4 \%$ of the carbon emissions of the EU.

There are two types of ICT equipment, ICT end-user-devices and ICT infrastructure. The latter consists of the mobile (cellular) network, the core telecom network, the broadcasting network, the servers (data center) and the satellite communication. ICT end-user-devices are the mobile phone, mobile $\mathrm{AV}$, imaging equipment, telecom interface, personal computer, audio systems, set-top-boxes, television, VHS/DVD systems.

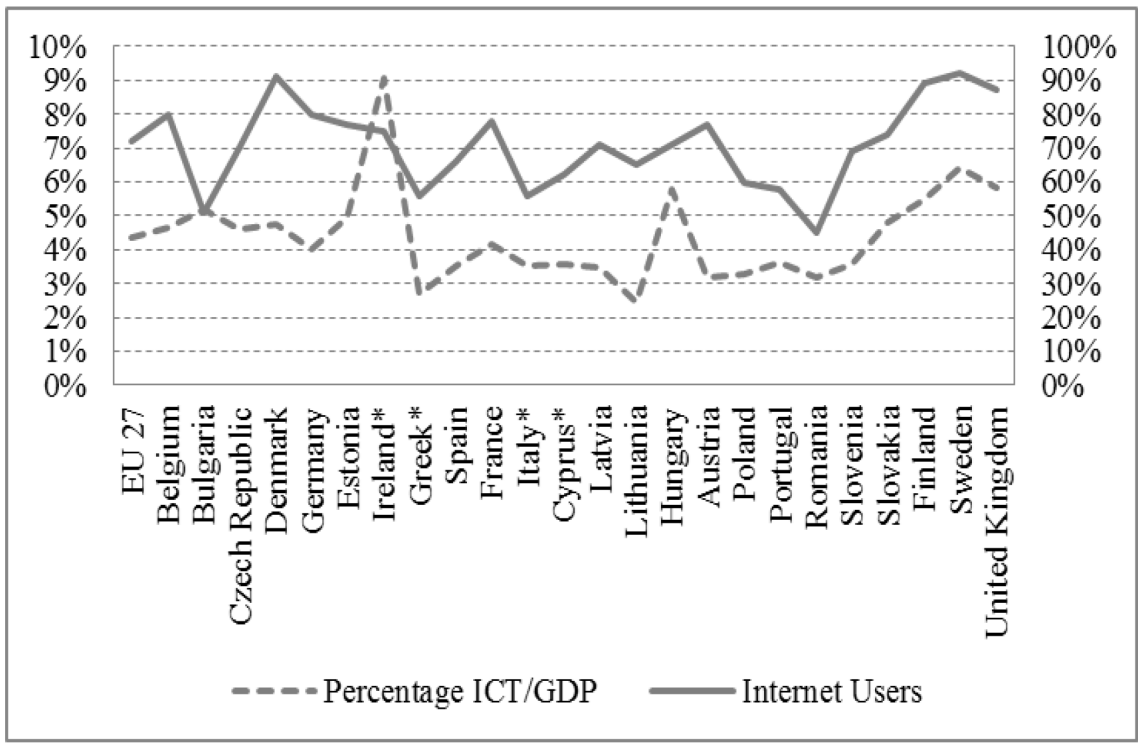

Data percentage ICT/GDP 2010 (*last available data from 2008), data internet users 2013.

Figure 3: Percentage of ICT in GDP and number of internet users (\% of individuals aged 16 to 74) for EU countries with available data 2010/2013 [7].

The importance and extent of the ICT sector as a percentage of the GDP of the EU 27 and for most of the member states, headed by Ireland with $9.06 \%$ (which seems to be an outlier), Sweden with $6.4 \%$ and Hungary with $5.79 \%$, is shown in fig. 3. Furthermore the number of internet users, with the majority in Sweden with $92 \%$ and Denmark with $91 \%$ of the individuals aged 16 to 74 , the least in Romania with $45 \%$ and Bulgaria with $51 \%$. The figure shows also the predominant correlation of the percentage of ICT in GDP to the number of internet users. 
The European Commission [8] assesses the total impact of ICT in a BAU and an Eco-scenario until 2020. Within the European Union (EU25) the total electricity consumption of ICTs is estimated to increase in the BAU scenario from $214.5 \mathrm{TWh} / \mathrm{a}$ in 2005 to $409.7 \mathrm{TWh} / \mathrm{a}$ in 2020 , thus by a factor of 1.9. The Eco-scenario with $288.2 \mathrm{TWh} / \mathrm{a}$ may reduce the growth significantly to an increasing factor of 1.3 .

The increase of the total electricity consumption is caused mainly by market growth, development of wired and wireless broadband communication, larger display with higher resolution, higher data compressing formats, continuous miniaturisation, more mobile devices, more functional devices, advanced power management, advanced component and circuitry design, and advanced display technologies.

\subsection{Energy efficiency by ICT}

The SMART 2020 report identifies a potential for carbon emissions reduction of $15 \%$ of the emissions or $7.8 \mathrm{GtCO}_{2} \mathrm{e}$ compared to the BAU scenario. Fig. 4 shows that the global ICT-enabled energy savings with $7.8 \mathrm{GtCO}_{2} \mathrm{e}$ may reach more than the fivefold of the ICT's footprint.

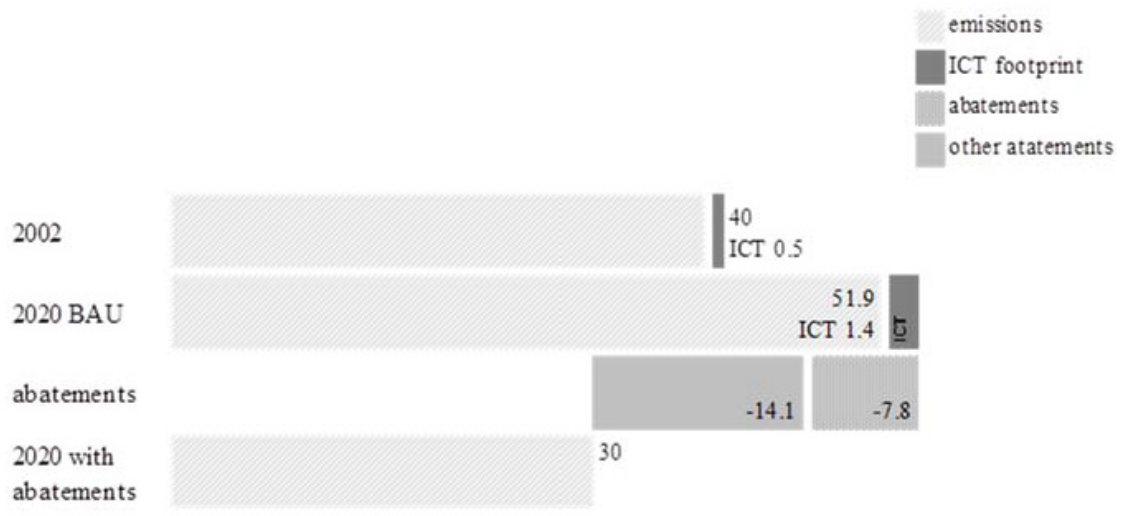

Figure 4: Global carbon emissions, the ICT footprint and enabling effect in $\mathrm{GtCO}_{2} \mathrm{e}[9]$.

ICTs can play a significant role in a shift to a low carbon global economy and society. Even though the potential for a net impact on the reduction of carbon emissions is evident, efficiency improvements may lead to an increase of demand by the rebound effect.

The energy savings can be realised mainly by standardising, monitoring, accounting, rethinking and transforming, mostly in the areas of smart motor systems, smart logistics, smart buildings and smart grids.

Certainly, the energy saving potential of ICTs is significant. ICT innovation is definitely a key element for implementing its potential, however mostly government and business are still on a business-as-usual path. For actually using 
this potential, future work in the development of ICT based technologies with regard to energy efficiency is needed as well as a corresponding legal framework.

\section{EU Legislation relating to ICT}

For reaching the potentials of ICTs to make a significant and important contribution to a low carbon society, a paradigm shift in technological development as well as the support of policy and governments is crucial, through research funds, legal regulation and standard implementation.

Certain standards and regulations are essential to guarantee the implementation of the efficiency gains by ICTs, as demonstrated by Redl [10]. A range of the main ICT related Directives, Regulations and Communications on the European scale and their feasible impact on ICT's potential for a low carbon society is evaluated in this chapter.

\subsection{RoHS Directive 2002/95/EC and RoHS Recast Directive 2011/65/EU}

The Directive 2002/95/EC of the European Parliament and of the Council of 27 January 2003, called RoHS Directive [11], regulated the restriction of the use of certain hazardous substances in electrical and electronic equipment. The aim of this Directive was on the one hand the avoidance of barriers to trade and a distortion of competition as well as the promotion of the internal market, while on the other hand the protection of human health and the reduction of risks to the environment. An objective was an environmentally sound recovery and disposal of waste electrical and electronic equipment. But the Directive already focused on the production process by requiring hazardous heavy metals to be replaced by safer alternatives, to reduce the concentration of hazardous substances in the waste of electrical and electronic equipment. Furthermore the recyclability of the equipment should be increased. Finally sales and distribution of electrical and electronic equipment containing lead, mercury, cadmium, hexavalent chromium, polybrominated biphenyls (PBB) or polybrominated diphenyl ethers (PBDE) should be excluded.

The European Commission decided to revise the RoHS Directive to increase the amount of recyclable e-waste and reduce the part which has to go to disposal. Hence in 2011 the RoHS Recast Directive 2011/65/EU on the restriction of the use of certain hazardous substances in electrical and electronic equipment [12] was adopted. The reduction of administrative burdens and the enhancement of the coherency with current policies and legislation is another objective to the RoHS Recast Directive.

Concerning a low carbon society, the Directive is an essential basis for the reduction of the ICT footprint. However, by reaching this objective, the sales of ICTs and consequently GDP may increase, with a negative impact on carbon emissions reduction. Further investigation is needed for estimating an indirect effect on the extent of a raise in GDP due to an increase of recycling, or to answer the question if possibly some kind of recycling processes are more energy intensive than the original production process. 


\subsection{WEEE Directive 2002/96/EC and WEEE Recast Directive 2012/19/EU}

Parallel to the RoHS Directive, the Directive 2002/96/EC of the European Parliament and of the Council of 27 January 2003 on waste electrical and electronic equipment (WEEE) [13] was adopted. The Directive regulated waste electrical and electronic equipment with the objective of prevention, recovery and safe disposal of waste. It applied to different categories such as household appliances, IT and telecommunications equipment, lighting equipment, electrical and electronic tools, toys, leisure and sports equipment, medical devices. Member States were required to minimise the disposal of waste electrical and electronic equipment as unsorted waste and to implement separate collection systems. Additionally the increase of the recyclability and the reparability should be promoted by the WEEE Directive. That should be guaranteed by the introduction of binding minimum ratios for recycling of electrical and electronic equipment between $50 \%$ and $80 \%$ of the average equipment's weight, depending on the equipment category.

In 2012, the WEEE Directive has been recasted, too. The WEEE Recast Directive 2012/19/EU of 4 July 2012 on waste electrical and electronic equipment [14] was adopted. It has improved the WEEE Directive according to the present developments and requirements, e.g. regarding the harmonisation of national registration and reporting requirements to decrease administrative burdens significantly, or regarding a more effective avoidance of illegal export of waste. The minimum ratios for recycling of electrical and electronic equipment have been increased by $5 \%$ to a range between $55 \%$ and $85 \%$ of the average equipment's weight. This shall ensure a separately collection of $29 \mathrm{~kg}$ per capita or around 10 million tons [15].

The impacts of the WEEE Recast Directive on a low carbon society are similar to those of the RoHS Recast Directive, promoting the reduction of the ICT footprint, but a basis for an increase of GDP, as well, as recycling salves the conscience of the consumers, "legitimatise" the consumption and is partly counterproductive with regard to a preferable reduction in consumption and thereby resources and energy.

\subsection{Directive 2006/32/EC energy end-use efficiency and energy services}

The Directive 2006/32/EC of 5 April 2006 on energy end-use efficiency and energy services [16] provides targets for energy savings, measures for promoting energy efficiency and energy services, and obligations on national public authorities relating to energy savings and energy efficient procurement. Furthermore the security of energy supplies is aimed to be increased and carbon emissions reduced. The Directive focuses on the energy demand side. In the framework of a national energy efficiency action plan (NEEAP) the member states have to implement an indicative energy saving target of $9 \%$ by 2016 . The public sector is requested to serve as an example.

As ICTs are an essential tool for energy efficiency in general and energy services in particular, this Directive stimulates the increased application of ICTs. In this context the potential of ICTs to reduce carbon emissions via the increase 
of energy intensity is initiated. Like each step in the direction of energy and resource saving, increased demand and GDP may be a non intended consequence by this Directive, too.

\subsection{Ecodesign Directive 2005/32/EC and Ecodesign Directive 2009/125/EC}

The Directive 2005/32/EC of the European Parliament and of the Council of 6 July 2005 establishing a framework for the setting of ecodesign requirements for energy-using products [17] defines environmental requirements for energyusing appliances of particular product groups, such as heating and water heating equipment, electric motors, domestic appliances or consumer electronics. The Directive is also a basis for requirements on electrical and electronic equipment related to energy efficiency and impacts on the environment.

The Directive 2009/125/EC of 21 October 2009 establishing a framework for the setting of ecodesign requirements for energy-related products (recast) [18] has amended Directive 2005/32/EC substantially. It is an extension to all energyrelated products aiming at the harmonisation at Community level. For implementing this Directive a set of Commission Regulations has been adopted, e.g. for air condition-ers, boilers, electric motors, lamps, power supplies, refrigerating appliances, television or water pumps.

ICTs are affected by this Directive by promoting the improvement of the ICT products' footprint as well as by strengthening ICTs as a tool for new energy efficient solutions. Hence ICTs may have a positive net effect on a low carbon society in this relation, but positive effects on the GDP and thereby on the increase of carbon emissions are a feasible result, as well.

\subsection{Renewable Source Directive 2009/28/EC}

The Directive 2009/28/EC of 23 April 2009 on the promotion of the use of energy from renewable sources [19] has introduced legally binding renewable energy targets. The Directive aims to increase energy savings, energy efficiency and the use of energy from renewable resource. Thus the objectives are the reduction of greenhouse gas emissions, security of energy supply and the promoting of technological developments and innovations.

The Directive may have positive effects on the footprint of ICTs in enhancing the ratio of renewable energy use in this sector. Especially the focus on the increase of technological improvements and of the use of energy efficiency technologies promotes the positive environmental impact of ICTs. The feasible positive effect on GDP should not go unmentioned at this point, too.

\subsection{Communications of the European Commission}

Beside the Directives and the Regulations, the Commission of the European Union uses Communications for proposals for future objectives, as well as to publish general concepts or action plans. In general Communications do not have a direct legal effect, but express an aim or intention of an institution of the European Union and give direction to the future development of the Community. 
The Communications $\operatorname{COM}(2011) 202$ final, on Smart Grids: from innovation to deployment [20], $\operatorname{COM(2011)~} 112$ final, Roadmap for moving to a competitive low carbon economy in 2050 [21] or $\operatorname{COM}(2008) 241$ final, Addressing the challenge of energy efficiency through Information and Communication Technologies [22], have for example a direct impact on ICTs by implying its mobilisation.

Table 1: Qualitative assessment of the effects of EU legislation on the impact of ICTs on carbon emission reduction.

\begin{tabular}{|l|c|c|c|c|}
\hline Directive & $\begin{array}{c}\text { ICT } \\
\text { footprint }\end{array}$ & $\begin{array}{c}\text { Energy } \\
\text { efficiency }\end{array}$ & $\begin{array}{c}\text { Cost of } \\
\text { renewable energy }\end{array}$ & GDP \\
\hline RoHS & ++ & & & - \\
\hline WEEE & ++ & & & - \\
\hline $\begin{array}{l}\text { Energy end-use } \\
\text { efficiency }\end{array}$ & & ++ & & - \\
\hline Ecodesign & + & + & + & - \\
\hline $\begin{array}{l}\text { Renewable } \\
\text { source }\end{array}$ & + & + & + & - \\
\hline Communications & + & + & + & + \\
\hline
\end{tabular}

This first qualitative analysis of the feasible effects of EU legislation on the ICT's impact on a low carbon society shows a clear positive net effect and emphazises the importance of an appropriate legal framework.

\section{Conclusions}

The positive contribution of ICTs towards achieving a low carbon society is neither secured nor self-evident. The ICT's impacts on energy intensity and on the cost of renewable energy may be neutralised by an implied increase of production and GDP and thereby an increase of carbon emissions. In using the high emission reduction potential of ICTs for reaching the EU's climate targets, the Community has to set the appropriate legal framework.

During the last decade the European Union already has adopted a set of Directives and Regulations, which directly or indirectly affects the impact of ICTs on environment and society. Additionally the European Commission defines policy requirements via the so-called Communications, which are in general not legally binding, but may give the direction for future developments. A first analysis shows the positive impacts of ICTs for a low carbon society due to the current European Union's legal framework.

In the Communication on a policy framework for climate and energy in the period from 2020 to 2030 of January 2014 [23], the European Commission proposes a greenhouse gas emission reduction target for EU emissions of $40 \%$ in 2030 relative to emissions in 1990, a greater share of renewable energy in the EU of at least $27 \%$, and the increase of energy efficiency of $20 \%$ to $25 \%$. This 
Communication also refers to the crucial role of new technologies for reaching these objectives. Thereby ICTs become more and more important.

The EU legislation will be a determining factor for maximising the benefits of ICT's positive net effects for a low carbon society.

\section{References}

[1] ITU World Telecommunication/ICT Indicators database, www.itu.int

[2] The Climate Group, SMART 2020: Enabling the low carbon economy in the information age, on behalf of the Global eSustainability Inititative (GeSI), 2008.

[3] European Commission, C(2009) 7604 final, Commission Recommendation of 9.10 .2009 on mobilising Information and Communications Technologies to facilitate the transition to an energyefficient, low-carbon economy, Brussels, 2008.

[4] Moyer, J.D., Hughes, B.B., ICTs: Do they contribute to increased carbon emissions? Technological Forecasting and Social Change, 79 (5), 919931, 2012.

[5] Berkhout, P.H.G., et al., Defining the rebound effect, Energy Policy, 28, 425-432, 2000.

[6] Mingay, S., Green IT: A New Industry Shock Wave, Gartner, http://www.ictliteracy.info/rf.pdf/Gartner_on_Green_IT.pdf, 2007.

[7] Eurostat, epp.eurostat.ec.europa.eu/tgm/table.do?tab=table\&plugin $=1 \&$ language $=$ de $\&$ pcode $=$ tin00074, epp.eurostat.ec.europa.eu/tgm/table.do?tab $=$ table \&init $=1 \&$ plugin $=1 \&$ language $=$ de $\&$ pcode $=$ tin00091

[8] European Commission, Impacts of Information and Communication Technologies on Energy Efficiency, DG INFSO, Final report, 2008.

[9] The Climate Group, SMART 2020: Enabling the low carbon economy in the information age, on behalf of the Global eSustainability Inititative (GeSI), p.15, 2008.

[10] Redl, F., Green IT - Nachhaltigkeit im IT Management, Master Thesis, University of Applied Sciences BFI Vienna, Vienna, 2013.

[11] European Parliament and Council, Directive 2002/95/EC of the European Parliament and of the Council of 27 January 2003 on the restriction of the use of certain hazardous substances in electrical and electronic equipment, Official Journal of the European Union, L 37/19, 2003.

[12] European Parliament and Council, Directive 2011/65/EU of the European Parliament and of the Council of 8 June 2011 on the restriction of the use of certain hazardous substances in electrical and electronic equipment (recast), Official Journal of the European Union, L 174/88, 2011.

[13] European Parliament and Council, Directive 2002/96/EC of the European Parliament and of the Council of 27 January 2003 on waste electrical and electronic equipment (WEEE), Official Journal of the European Union, L 37/24, 2003.

[14] European Parliament and Council, Directive 2012/19/EU of the European Parliament and of the Council of 4 July 2012 on waste electrical and 
electronic equipment (WEEE) (recast), Official Journal of the European Union, L 197/38, 2012.

[15] European Commission, Recast of the WEEE Directive, http://ec.europa.eu/environment/waste/weee/index en.htm, 2014.

[16] European Parliament and Council, Directive 2006/32/EC of the European Parliament and of the Council of 5 April 2006 on energy end-use efficiency and energy services and repealing Council Directive 93/76/EEC, Official Journal of the European Union, L 114/64, 2006.

[17] European Parliament and Council, Directive 2005/32/EC of the European Parliament and of the Council of 6 July 2005 establishing a framework for the setting of ecodesign requirements for energy-using products and amending Council Directive 92/42/EEC and Directives 96/57/EC and 2000/55/EC of the European Parliament and of the Council, Official Journal of the European Union, L 191/29, 2005.

[18] European Parliament and Council, Directive 2009/125/EC of the European Parliament and of the Council of 21 October 2009 establishing a framework for the setting of ecodesign requirements for energy-related products (recast), Official Journal of the European Union, L 285/10, 2009.

[19] European Parliament and Council, Directive 2009/28/EC of the European Parliament and of the Council of 23 April 2009 on the promotion of the use of energy from renewable sources and amending and subsequently repealing Directives 2001/77/EC and 2003/30/EC, Official Journal of the European Union, L 140/16, 2009.

[20] European Commission, $\operatorname{COM}(2011) 202$ final, Communication from the Commission to the European Parliament, the Council, the European Economic and Social Committee and the Committee of the Regions, Smart Grids: from innovation to deployment, Brussels, 2011.

[21] European Commission, $\operatorname{COM}(2011) 112$ final, Communication from the Commission to the European Parliament, the Council, the European Economic and Social Committee and the Committee of the Regions, A Roadmap for moving to a competitive low carbon economy in 2050, Brussels, 2011.

[22] European Commission, $\operatorname{COM}(2008) 241$ final, Communication from the Commission to the European Parliament, the Council, the European Economic and Social Committee and the Committee of the Regions, Addressing the challenge of energy efficiency through Information and Communication Technologies, Brussels, 2008.

[23] European Commission, $\operatorname{COM}(2014) 15$ final, Communication from the Commission to the European Parliament, the Council, the European Economic and Social Committee and the Committee of the Regions, A policy framework for climate and energy in the period from 2020 to 2030, Brussels, 2014. 